\title{
Toll-like receptor signalling pathways as key targets for mediating the anti-inflammatory and immunosuppressive effects of glucocorticoids
}

\author{
P N Moynagh \\ Department of Pharmacology, Conway Institute of Biomolecular and Biomedical Research, University College Dublin, Belfield, Dublin 4, Ireland \\ (Requests for offprints should be addressed to P N Moynagh; Email: P.Moynagh@ucd.ie)
}

\begin{abstract}
Toll-like receptors (TLRs) play crucial roles in the induction of innate immune responses by recognising pathogenassociated molecular patterns. The engagement of TLRs by pathogens results in induction of co-stimulatory molecules that facilitate a specific immune response and also in the induction of pro-inflammatory proteins that will promote the elimination of pathogens from the body. TLRs employ many of the same signalling components as the type I interleukin (IL)-1 receptor (IL-1R). This is hardly surprising since the intracellular regions of TLRs and the IL-1R share a conserved Toll/IL-1R homology domain (TIR) that allows the receptors to recruit the
\end{abstract}

intracellular TIR-containing adaptor protein Myd88. The latter then activates IL-1R-associated kinases that in turn recruit well-characterised downstream effectors culminating in activation of MAP kinases and transcription factors such as NFKB and AP-1. Since glucocorticoids are known to target the latter transcription factors and the MAP kinase cascades, this commentary highlights the likely crucial importance of Toll-like receptor signalling pathways as key targets for mediating the antiinflammatory and immunosuppressive effects of steroids. Journal of Endocrinology (2003) 179, 139-144

\section{Toll-like receptors (TLRs) and immunity}

Human TLRs are key components in innate immune responses due to their ability to recognise pathogenassociated molecules (reviewed by Krutzik et al. 2001). Many of the TLRs have defined functions in the host defence system. As examples, TLR 2 recognises peptidoglycan and bacterial lipoprotein from Gram-positive bacteria (Aliprantis et al. 1999, Brightbill et al. 1999, Takeuchi et al. 1999), TLR3 mediates responses to double-stranded RNA (Alexopoulou et al. 2001), TLR4 is involved in recognition of Gram-negative lipopolysaccharide (LPS) (Poltorak et al. 1998, Chow et al. 1999, Hoshino et al. 1999, Qureshi et al. 1999, Takeuchi et al. 1999), TLR-5 recognises bacterial flagellin (Hayashi et al. 2001) and TLR9 functions as a receptor for bacterial DNA containing CpG motifs (Hemmi et al. 2000). Some TLRs, such as TLR2 and -6 also show functional co-operativity (Ozinsky et al. 2000). The engagement of TLRs by pathogenic components results in induction of costimulatory molecules that facilitate T-cell activation and pro-inflammatory proteins that effect elimination of the pathogen from the body (Medzhitov et al. 1997).

\section{TLR/interleukin-1 (IL-1) signalling and NFKB}

TLRs employ many of the same signalling components as the type I IL-1 receptor (IL-1RI) (O'Neill \& Greene 1998) (Fig. 1) by virtue of a conserved cytoplasmic Toll/IL-1R homology domain (TIR). The latter is important in initiating various signalling pathways, especially that regulating the transcription factor NFKB. The latter exists in the cytosol of resting cells as a homoor heterodimer of proteins of the Rel family of transcription factors (Ghosh et al. 1998). The transcriptional activity of the Rel proteins is tightly regulated by their association

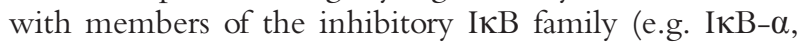
I $\mathrm{B}-\beta$ and $\mathrm{I \kappa B}-\varepsilon$ ) that sequester nuclear factor kappaB $(\mathrm{NFKB})$ in the cytosol. TLRs and IL-1R cause phosphorylation of I $\mathrm{B}$ on two specific N-terminal serines by the IKB kinases (IKKs), IKK $\alpha$ and IKK $\beta$, which form a large multiprotein complex with a scaffold protein called NEMO $(\mathrm{IKK} \gamma)$. The phosphorylation of IKB proteins represents a signal for polyubiquitination followed by their degradation via the 26S proteasome (May \& Ghosh 1998, Karin \& Ben-Neriah 2000). This allows for translocation of NFKB to the nucleus, where it activates genes encoding 


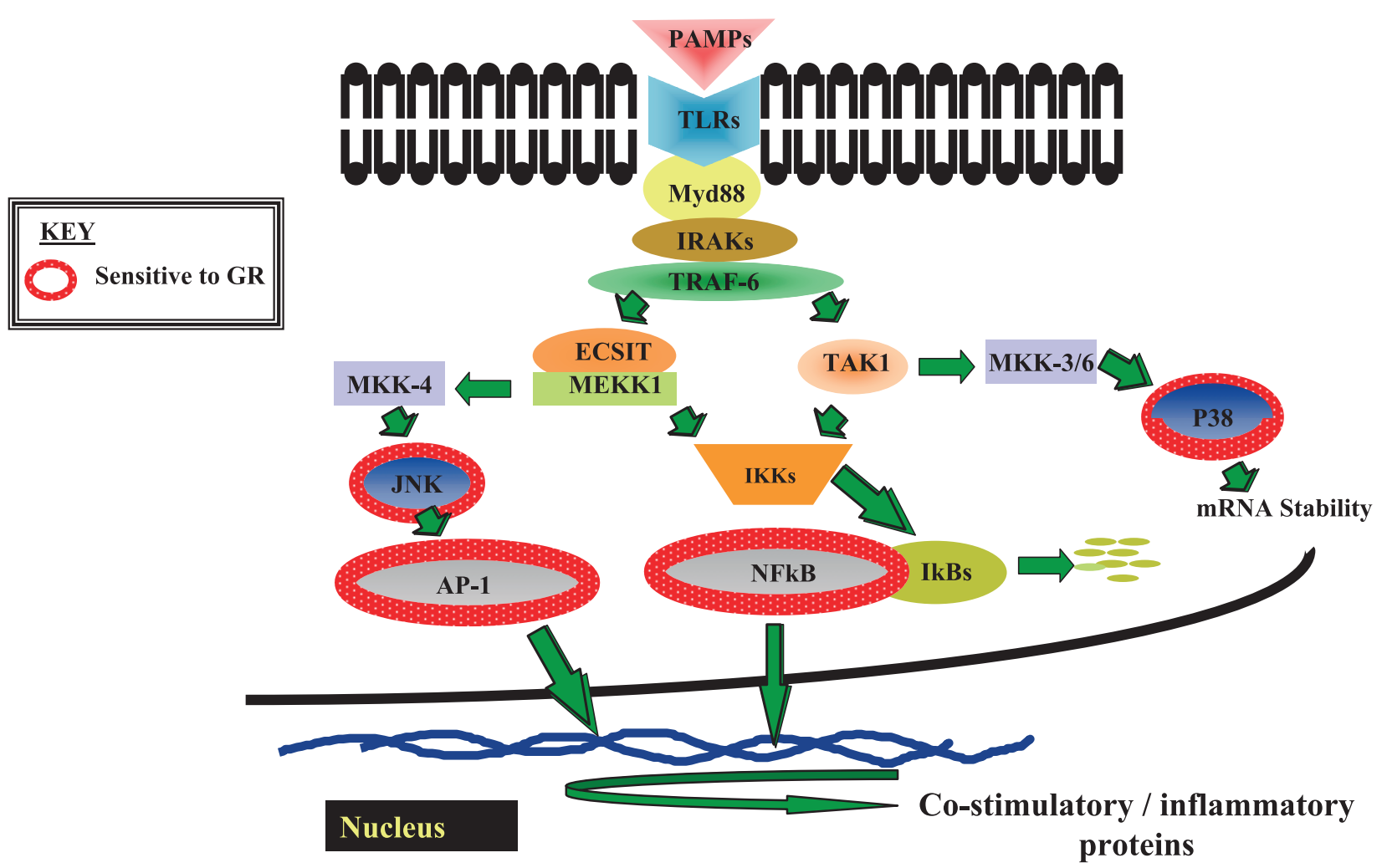

Figure 1 Toll-like receptor signalling and lead targets for glucocorticoids. The signalling molecules generally employed by TLRs in mediating activation of the transcription factors NFKB and AP-1 and the MAPKs are indicated. Some additional signalling molecules in these pathways have been omitted for the sake of clarity. The lead targets that may be subject to inhibition by activated GR are encircled in red. PAMPs, pathogen-associated molecular patterns.

inflammatory proteins and co-stimulatory molecules. Thus the IKKs are crucial regulators of NFKB and much effort has probed the upstream signalling components employed by TLRs and IL-1R in regulating IKK activity.

The TIR domain plays a crucial role in transducing signals from TLRs and IL-1RI (Fig. 1). Thus the binding of IL-1 to IL-1RI causes association with another TIR domain-containing protein, IL-1R-accessory protein (Greenfeder et al. 1995, Wesche et al. 1997a). This receptor complex then recruits the intracellular TIRcontaining adapter protein Myd88 (Burns et al. 1998). TLRs can directly associate with Myd88 (Medzhitov et al. 1998) and other TIR domain-containing adapter proteins such as MyD88 adapter-like/TIR domain-containing adapter protein (Fitzgerald et al. 2001, Horng et al. 2001) and TIR domain-containing adapter inducing IFN- $\beta$ / TIR-containing adaptor molecule (Yamamoto et al. 2002, Oshiumi et al. 2003). These adapter proteins subsequently recruit and activate members of the IL-1R-associated kinase (IRAK) family (Muzio et al. 1997, Wesche et al. 1997b, Kobayashi et al. 2002, Li et al. 2002, Suzuki et al. 2002). IRAK is recruited to Myd88 in association with another protein termed Toll-interacting protein (Tollip) (Burns et al. 2000). IRAK associates with Myd88 via the homophilic interaction of their death domains. IRAK also contains a kinase domain but the kinase activity is not required for NFKB activation but may be required for other pathways such as the p38 MAP kinase (MAPK) cascade (Knop \& Martin 1999, Schmidt et al. 2001). The IRAK-Myd88 association triggers hyperphosphorylation of IRAK by itself (Cao et al. 1996) and/or by other additional kinases (Li et al. 1999), leading to its dissociation from Myd88 and Tollip and its interaction with the downstream adaptor tumour necrosis factor (TNF) receptor-associated factor 6 (TRAF-6) (Burns et al. 2000). The phosphorylation of IRAK also ultimately leads to its degradation by proteasomes and this may be a regulatory mechanism by which cells become desensitised after prolonged activation of IL-RI and TLRs (Yamin \& Miller 1997, Li et al. 2000). The interaction of IRAK with TRAF-6 leads to activation of transforming growth factor$\beta$-activating kinase (TAK1) (Ninomiya-Tsuji et al. 1999). IRAK is essential in this activation process since it promotes the translocation of TAK1 binding protein 2 (TAB2) from the membrane to the cytosol where TAB2 interacts with TRAF- 6 and bridges the association of TRAF-6 with TAK1 (Takaesu et al. 2000, 2001). The latter, with the help of another TAK1-binding protein, 
TAB1, becomes activated and in turn activates NFKBinducing kinase (NIK) (Ninomiya-Tsuji et al. 1999). NIK can then activate NFKB through phosphorylation and activation of the IKKs (Ling et al. 1998, Nakano et al. 1998). However, the role of NIK has recently been equivocated with analysis of NIK knockout mice and alymphoplasia mice that contain a point mutation in NIK showing no defect in activation of NFKB by TNF, IL-1 and LPS (Shinkura et al. 1999, Yin et al. 2001). Interestingly IKKs may also be activated by MAPK/ERK kinase kinase 1 (MEKK-1) that is activated by TRAF-6 via a novel adaptor protein termed ECSIT (Kopp et al. 1999). Thus TRAF-6 appears to act as a bifurcation point to activate the TAK1 and MEKK-1 pathways, both of which activate NFKB.

\section{TLR/IL-1 signalling and MAPKs}

In addition to NFKB activation, IL-1RI and TLRs can also initiate MAPK signalling cascades and activate multiple transcription factors, including AP-1 and Elk-1. Thus IL-1 and LPS induce phosphorylation of p38, ERK1/2 and JNK (Freshney et al. 1994, Rouse et al. 1994, Derijard et al. 1995, Lin et al. 1995, Ulevitch \& Tobias 1995). Whilst the mechanisms by which the MAPKs are activated by IL-1R1 and TLRs are incompletely understood, several upstream regulators have been identified. Interestingly, as described above, such regulators also play integral roles in mediating activation of NFKB (Fig. 1). Thus TAK1/TAB1 can activate the MAPKKs MKK3/6 and MKK4, which in turn activate p38 and JNK respectively (Ninomiya-Tsuji et al. 1999). In addition MEKK-1 can also activate the JNK pathway by phosphorylating MKK4 (Xia et al. 1998).

\section{Transcription factors as targets for glucocorticoids}

Whilst the molecular mechanisms underlying the antiinflammatory and immunosuppressive effects of glucocorticoids are complex and incompletely understood, the signalling pathways described above for TLRs are likely to emerge as lead targets for mediating such effects. A succinct overview of the known molecular effects of glucocorticoids gives significant credence to this proposal.

The primary target for glucocorticoids is a specific intracellular glucocorticoid receptor (GR) (Beato et al. 1995). The engagement of GR by glucocorticoids promotes its dissociation from the $90 \mathrm{kDa}$ heat shock protein and translocation into the nucleus. The liganded GR binds as a dimer to DNA by recognising specific palindromic sequences known as glucocorticoid response elements (GREs) (Luisi et al. 1991). The binding of GR to GREs can induce the transcription of genes whose promoters are in close proximity to GREs, by facilitating recruitment of co-activator complexes (such as CREB-binding protein $(\mathrm{CBP}) / \mathrm{p} 300)$ and RNA polymerase II. By this process glucocorticoids can directly promote the expression of anti-inflammatory proteins such as lipocortin, IL-1R antagonist and IL-10 (Adcock \& Caramori 2001). It is also interesting to note that glucocorticoids can directly induce the expression of I $\mathrm{KB}-\alpha$, the inhibitor of NFKB (Almawi \& Melemedjian 2002). The author has shown this phenomenon to be cell-type specific (Bourke \& Moynagh 1999), but it is still worth emphasising that in responsive cells the induction of IKB- $\alpha$ by glucocorticoids is likely to have a negative influence on TLR signalling. Additional mechanisms by which glucocorticoids regulate NFKB are discussed below.

Whilst the direct induction of anti-inflammatory proteins by glucocorticoids is a significant contributory mechanism to their clinical anti-inflammatory effects, the pleiotropic ability of glucocorticoids to inhibit the expression of a plethora of pro-inflammatory proteins is likely to be of crucial importance (Barnes 1995). Thus glucocorticoids inhibit the expression of an array of cytokines (including IL-1 and TNF), chemokines and leukocyte adhesion molecules. In general the promoters of the genes encoding these proteins lack GREs and thus gene repression is not dependent on GR-GRE interaction. Instead repression is mediated by inhibitory effects of activated GR on transcription factors that are known to promote the expression of the pro-inflammatory proteins. Two of the best characterised transcription factors that are known targets for activated GR are NFKB and AP-1. In addition to the positive regulation of $I \kappa B-\alpha$ expression, as described above, activated GR is also known to directly associate with AP-1 and the p65 subunit of NFkB (Adcock \& Caramori 2001). Such interactions lead to reduced association of AP-1 and NFKB with the co-activator CBP resulting in inhibition of their transactivation potential. A recent report has suggested a related but novel mechanism underlying GR repression of pro-inflammatory gene expression in which GR inhibits histone acetylation by directly inhibiting CBP-associated histone acetyltransferase activity and by actively recruiting a histone deacetylase complex (Ito et al. 2000). Such histone deacetylation will prevent unwinding of DNA from histone complexes and so limit access of transcription factors such as NFkB and AP-1 to their binding sites, resulting in inhibition of expression of pro-inflammatory genes. Furthermore, another report suggests an additional specific mechanism for the inhibitory effects of GR on NFKB. Thus GR has been shown to inhibit NFKB by interfering with serine-2 phosphorylation of the C-terminal domain of RNA polymerase II, resulting in reduced recruitment of the latter to NFKB-regulated promoter regions (Nissen \& Yamamoto 2000). A complex picture thus emerges of the regulatory effects of activated GR on the transcription factors NFKB and AP-1. However, it is intuitively obvious that glucocorticoids may target TLR signalling since TLR 
signalling culminates in activation of $\mathrm{NFKB}$ and $\mathrm{AP}-1$ (Fig. 1).

\section{MAPKs as targets for glucocorticoids}

Whilst NFkB and AP-1 are key targets for GR, it is also apparent that regulation of these transcription factors is not the exclusive basis for GR repression of inflammatory genes. The MAPK signalling pathways play important roles in promoting inflammatory gene expression and it has emerged that these pathways are also prone to regulation by glucocorticoids. Dexamethasone has been shown to inhibit activation of ERK1/2, JNK and p38 MAPKs (Caelles et al. 1997, Swantek et al. 1997, Gonzalez et al. 1999, Lasa et al. 2001) and repress inflammatory gene expression. As an example GR blocks the JNK signalling pathway resulting in lack of phosphorylation of c-Jun on serine-63 and -73 and ultimately inhibition of AP-1 and repression of gene expression (Caelles et al. 1997). This represents another mechanism by which GR can regulate AP-1 activity and is distinct from the direct GR-AP-1 association described above. Furthermore since JNK is required for LPS stimulation of TNF translation, the inhibition of JNK by GR results in reduced TNF translation in response to LPS (Swantek et al. 1997). Since the latter is recognised by TLR-4 it is apparent that JNK in the TLR-4 signalling pathway is a key target for glucocorticoids. However, the other MAPKs are also likely to play roles in mediating anti-inflammatory effects of glucocorticoids on TLR signalling. Thus LPS is well known to induce cyclooxygenase 2 and dexamethasone has been shown to destabilise cyclooxygenase 2 mRNA by inhibiting the phosphorylation and activity of p38 MAPK (Lasa et al. 2001). The inhibition of the MAPKs by glucocorticoids is mediated by an increased expression and decreased degradation of the MAPK phosphatase-1 (Kassel et al. 2001). Overall a convincing picture emerges of MAPK pathways playing key roles as targets for glucocorticoids. The employment of MAPK pathways by TLRs again emphasises the obvious relevance of TLR signalling pathways as targets for glucocorticoids (Fig. 1).

\section{Likely consequences of regulation of TLR signalling by glucocorticoids}

The above discussion highlights TLR signalling pathways as lead targets for glucocorticoids. The global use of the transcription factors NFKB and AP-1 and the MAPK pathways by the various TLRs strongly hints that all of the TLR signalling pathways will be subject to interference by glucocorticoids. This has important functional consequence in terms of widespread suppression of the innate immune response to a variety of pathogens. TLRs are strategically located at the host-pathogen interface and serve to recognise a number of molecules that are expressed by pathogens and not the host. This recognition triggers a complex cascade of intracellular signalling pathways, as described above, that will ultimately promote the expression of pro-inflammatory proteins such as IL-1 and TNF. The latter orchestrate the inflammatory response and thus the inhibition of TLR signalling by glucocorticoids will repress IL-1 and TNF expression and this is likely to make a major contribution to dampening the inflammatory response. Since the latter is a crucial component of the innate immunity, it is clear that the regulation of TLR signalling by glucocorticoids lies at the heart of their immunosuppressive and anti-inflammatory properties. The targeting of TLR signalling by steroids probably contributes to the compromised immune status of individuals on long-term use of steroids for the treatment of inflammatory diseases. The blunting of TLR signalling by steroids will interfere with the initial recognition phase of the immune response and will dampen the innate response to pathogens. However, the fallout of inhibition of TLR signalling is not restricted to innate immunity. The triggering of TLRs, such as TLR-4 by LPS, also induces the expression of co-stimulatory molecules on antigen-presenting cells and this is a key process in initiating a specific immune response (Medzhitov et al. 1997). The signalling pathways employed by TLRs in promoting the expression of co-stimulatory molecules are common to the above transduction systems used in inducing pro-inflammatory gene expression. Thus the regulation of these pathways by glucocorticoids will repress the expression of co-stimulatory molecules and suppress the specific immune response.

In summary, glucocorticoids have the potential to inhibit the intracellular signalling pathways employed by TLRs. The latter act at the crossroads of innate and adaptive immunity and thus the paralysis of TLR signalling is likely to be central in manifesting the remarkable immunosuppressive effects of glucocorticoids.

\section{Funding}

I would like to acknowledge research funding from the European Biotechnology 5th Framework programme (Contract Nos QLG1-CT-1999-00549 and QLK3-CT2000-00270), Health Research Board of Ireland, Enterprise Ireland and Higher Education Authority of Ireland.

\section{References}

Adcock IM \& Caramori G 2001 Cross-talk between pro-inflammatory transcription factors and glucocorticoids. Immunology and Cell Biology 79 376-384.

Alexopoulou L, Holt AC, Medzhitov R \& Flavell RA 2001 Recognition of double-stranded RNA and activation of NF-kappaB by Toll-like receptor 3. Nature 413 732-738. 
Aliprantis AO, Yang RB, Mark MR, Suggett S, Devaux B, Radolf JD, Klimpel GR, Godowski P \& Zychlinsky A 1999 Cell activation and apoptosis by bacterial lipoproteins through toll-like receptor-2. Science 285 736-739.

Almawi WY \& Melemedjian OK 2002 Negative regulation of nuclear factor- $\mathrm{\kappa B}$ activation and function by glucocorticoids. Journal of Molecular Endocrinology 28 69-78.

Barnes PJ 1995 Anti-inflammatory mechanisms of glucocorticoids. Biochemical Society Transactions 23 940-945.

Beato M, Herrlich P \& Schutz G 1995 Steroid hormone receptors: many actors in search of a plot. Cell 83 851-857.

Bourke E \& Moynagh PN 1999 Antiinflammatory effects of glucocorticoids in brain cells, independent of NF- $\kappa \mathrm{B}$. Journal of Immunology 163 2113-2119.

Brightbill HD, Libraty DH, Krutzik SR, Yang RB, Belisle JT, Bleharski JR, Maitland M, Norgard MV, Plevy SE, Smale ST et al. 1999 Host defense mechanisms triggered by microbial lipoproteins through toll-like receptors. Science 285 732-736.

Burns K, Martinon F, Esslinger C, Pahl H, Schneider P, Bodmer JL, Di Marco F, French L \& Tschopp J 1998 MyD88, an adapter protein involved in interleukin-1 signaling. Journal of Biological Chemistry 273 12203-12209.

Burns K, Clatworthy J, Martin L, Martinon F, Plumpton C, Maschera B, Lewis A, Ray K, Tschopp J \& Volpe F 2000 Tollip, a new component of the IL-1RI pathway, links IRAK to the IL-1 receptor. Nature Cell Biology 2 346-351.

Caelles C, Gonzalez-Sancho JM \& Munoz A 1997 Nuclear hormone receptor antagonism with AP-1 by inhibition of the JNK pathway. Genes and Development 11 3351-3364.

Cao Z, Henzel WJ \& Gao X 1996 IRAK: a kinase associated with the interleukin-1 receptor. Science 271 1128-1131.

Chow JC, Young DW, Golenbock DT, Christ WJ \& Gusovsky F 1999 Toll-like receptor-4 mediates lipopolysaccharide-induced signal transduction. Journal of Biological Chemistry 274 10689-10692.

Derijard B, Raingeaud J, Barrett T, Wu IH, Han J, Ulevitch RJ \& Davis RJ 1995 Independent human MAP-kinase signal transduction pathways defined by MEK and MKK isoforms. Science 267 682-685.

Fitzgerald KA, Palsson-McDermott EM, Bowie AG, Jefferies CA, Mansell AS, Brady G, Brint E, Dunne A, Gray P, Harte MT et al. 2001 Mal (MyD88-adapter-like) is required for Toll-like receptor-4 signal transduction. Nature 413 78-83.

Freshney NW, Rawlinson L, Guesdon F, Jones E, Cowley S, Hsuan J \& Saklatvala J 1994 Interleukin-1 activates a novel protein kinase cascade that results in the phosphorylation of Hsp27. Cell $\mathbf{7 8}$ 1039-1049.

Ghosh S, May MJ \& Kopp EB 1998 NF-kappa B and Rel proteins: evolutionarily conserved mediators of immune responses. Annual Review of Immunology 16 225-260.

Gonzalez MV, Gonzalez-Sancho JM, Caelles C, Munoz A \& Jimenez B 1999 Hormone-activated nuclear receptors inhibit the stimulation of the JNK and ERK signalling pathways in endothelial cells. FEBS Letters 459 272-276.

Greenfeder SA, Nunes P, Kwee L, Labow M, Chizzonite RA \& Ju G 1995 Molecular cloning and characterization of a second subunit of the interleukin 1 receptor complex. Journal of Biological Chemistry 270 13757-13765.

Hayashi F, Smith KD, Ozinsky A, Hawn TR, Yi EC, Goodlett DR, Eng JK, Akira S, Underhill DM \& Aderem A 2001 The innate immune response to bacterial flagellin is mediated by Toll-like receptor 5. Nature 410 1099-1103.

Hemmi H, Takeuchi O, Kawai T, Kaisho T, Sato S, Sanjo H, Matsumoto M, Hoshino K, Wagner H, Takeda K et al. 2000 A Toll-like receptor recognizes bacterial DNA. Nature 408 740-745.

Horng T, Barton GM \& Medzhitov R 2001 TIRAP: an adapter molecule in the Toll signaling pathway. Nature Immunology 2 835-841.
Hoshino K, Takeuchi O, Kawai T, Sanjo H, Ogawa T, Takeda Y, Takeda K \& Akira S 1999 Cutting edge: Toll-like receptor 4 (TLR4)-deficient mice are hyporesponsive to lipopolysaccharide: evidence for TLR4 as the LPS gene product. Journal of Immunology 162 3749-3752.

Ito K, Barnes PJ \& Adcock IM 2000 Glucocorticoid receptor recruitment of histone deacetylase 2 inhibits interleukin- $1 \beta$-induced histone $\mathrm{H} 4$ acetylation on lysines 8 and 12. Molecular and Cellular Biology 20 6891-6903.

Karin M \& Ben-Neriah Y 2000 Phosphorylation meets ubiquitination: the control of NF-[kappa]B activity. Annual Review of Immunology 18 621-663.

Kassel O, Sancono A, Kratzschmar J, Kreft B, Stassen M \& Cato AC 2001 Glucocorticoids inhibit MAP kinase via increased expression and decreased degradation of MKP-1. EMBO Journal 20 $7108-7116$.

Knop J \& Martin MU 1999 Effects of IL-1 receptor-associated kinase (IRAK) expression on IL-1 signaling are independent of its kinase activity. FEBS Letters 448 81-85.

Kobayashi K, Hernandez LD, Galan JE, Janeway CA Jr, Medzhitov R \& Flavell RA 2002 IRAK-M is a negative regulator of Toll-like receptor signaling. Cell 110 191-202.

Kopp E, Medzhitov R, Carothers J, Xiao C, Douglas I, Janeway CA \& Ghosh S 1999 ECSIT is an evolutionarily conserved intermediate in the Toll/IL-1 signal transduction pathway. Genes and Development 13 2059-2071.

Krutzik SR, Sieling PA \& Modlin RL 2001 The role of Toll-like receptors in host defense against microbial infection. Current Opinion in Immunology 13 104-108.

Lasa M, Brook M, Saklatvala J \& Clark AR 2001 Dexamethasone destabilizes cyclooxygenase 2 mRNA by inhibiting mitogenactivated protein kinase p38. Molecular and Cellular Biology 21 $771-780$.

Li L, Cousart S, Hu J \& McCall CE 2000 Characterization of interleukin-1 receptor-associated kinase in normal and endotoxintolerant cells. Journal of Biological Chemistry 275 23340-23345.

Li S, Strelow A, Fontana EJ \& Wesche H 2002 IRAK-4: a novel member of the IRAK family with the properties of an IRAKkinase. PNAS 99 5567-5572.

Li X, Commane M, Burns C, Vithalani K, Cao Z \& Stark GR 1999 Mutant cells that do not respond to interleukin-1 (IL-1) reveal a novel role for IL-1 receptor-associated kinase. Molecular and Cellular Biology 19 4643-4652.

Lin A, Minden A, Martinetto H, Claret FX, Lange-Carter C, Mercurio F, Johnson GL \& Karin M 1995 Identification of a dual specificity kinase that activates the Jun kinases and p38-Mpk2. Science 268 286-290.

Ling L, Cao Z \& Goeddel DV 1998 NF-kappaB-inducing kinase activates IKK-alpha by phosphorylation of Ser-176. PNAS 95 3792-3797.

Luisi BF, Xu WX, Otwinowski Z, Freedman LP \& Yamamoto KR 1991 Crystallographic analysis of the interaction of the glucocorticoid receptor with DNA. Nature 352 497-505.

May MJ \& Ghosh S 1998 Signal transduction through NF-kappa B. Immunology Today 19 80-88.

Medzhitov R, Preston-Hurlburt P \& Janeway CA Jr 1997 A human homologue of the Drosophila Toll protein signals activation of adaptive immunity. Nature 388 394-397.

Medzhitov R, Preston-Hurlburt P, Kopp E, Stadlen A, Chen C, Ghosh S \& Janeway CA Jr 1998 MyD88 is an adaptor protein in the hToll/IL-1 receptor family signaling pathways. Molecular Cell 2 253-258.

Muzio M, Ni J, Feng P \& Dixit VM 1997 IRAK (Pelle) family member IRAK-2 and MyD88 as proximal mediators of IL-1 signaling. Science 278 1612-1615.

Nakano H, Shindo M, Sakon S, Nishinaka S, Mihara M, Yagita H \& Okumura K 1998 Differential regulation of IkappaB kinase alpha 
and beta by two upstream kinases, NF-kappaB-inducing kinase and mitogen-activated protein kinase/ERK kinase kinase-1. PNAS 95 3537-3542.

Ninomiya-Tsuji J, Kishimoto K, Hiyama A, Inoue J, Cao Z \& Matsumoto K 1999 The kinase TAK1 can activate the NIK-I kappaB as well as the MAP kinase cascade in the IL-1 signalling pathway. Nature 398 252-256.

Nissen RM \& Yamamoto KR 2000 The glucocorticoid receptor inhibits NFkappaB by interfering with serine-2 phosphorylation of the RNA polymerase II carboxy-terminal domain. Genes and Development 14 2314-2329.

O’Neill LA \& Greene C 1998 Signal transduction pathways activated by the IL-1 receptor family: ancient signaling machinery in mammals, insects, and plants. Journal of Leukocyte Biology 63 650-657.

Oshiumi H, Matsumoto M, Funami K, Akazawa T \& Seya T 2003 TICAM-1, an adaptor molecule that participates in Toll-like receptor 3-mediated interferon-beta induction. Nature Immunology 4 161-167.

Ozinsky A, Underhill DM, Fontenot JD, Hajjar AM, Smith KD, Wilson CB, Schroeder L \& Aderem A 2000 The repertoire for pattern recognition of pathogens by the innate immune system is defined by cooperation between toll-like receptors. PNAS $\mathbf{9 7}$ 13766-13771.

Poltorak A, He X, Smirnova I, Liu MY, Huffel CV, Du X, Birdwell D, Alejos E, Silva M, Galanos C et al. 1998 Defective LPS signaling in $\mathrm{C} 3 \mathrm{H} / \mathrm{HeJ}$ and $\mathrm{C} 57 \mathrm{BL} / 10 \mathrm{ScCr}$ mice: mutations in Tlr4 gene. Science 282 2085-2088.

Qureshi ST, Lariviere L, Leveque G, Clermont S, Moore KJ, Gros P \& Malo D 1999 Endotoxin-tolerant mice have mutations in Tolllike receptor 4 (Tlr4). Journal of Experimental Medicine 189 615-625.

Rouse J, Cohen P, Trigon S, Morange M, Alonso-Llamazares A, Zamanillo D, Hunt T \& Nebreda AR 1994 A novel kinase cascade triggered by stress and heat shock that stimulates MAPKAP kinase- 2 and phosphorylation of the small heat shock proteins. Cell 78 1027-1037.

Schmidt A, Caron E \& Hall A 2001 Lipopolysaccharide-induced activation of beta2-integrin function in macrophages requires Irak kinase activity, p38 mitogen-activated protein 1 and the Rap1 GTPase. Molecular and Cellular Biology 2 438-448.

Shinkura R, Kitada K, Matsuda F, Tashiro K, Ikuta K, Suzuki M, Kogishi K, Serikawa T \& Honjo T 1999 Alymphoplasia is caused by a point mutation in the mouse gene encoding NF-kappa B-inducing kinase. Nature Genetics 22 74-77.

Suzuki N, Suzuki S, Duncan GS, Millar DG, Wada T, Mirtsos C, Takada H, Wakeham A, Itie A, Li S et al. 2002 Severe impairment of interleukin-1 and Toll-like receptor signalling in mice lacking IRAK-4. Nature 416 750-756.
Swantek JL, Cobb MH \& Geppert TD 1997 Jun N-terminal kinase/stress-activated protein kinase (JNK/SAPK) is required for lipopolysaccharide stimulation of tumor necrosis factor alpha (TNF-alpha) translation: glucocorticoids inhibit TNF-alpha translation by blocking JNK/SAPK. Molecular and Cellular Biology 17 6274-6282.

Takaesu G, Kishida S, Hiyama A, Yamaguchi K, Shibuya H, Irie K, Ninomiya-Tsuji J \& Matsumoto K 2000 TAB2, a novel adaptor protein, mediates activation of TAK1 MAPKKK by linking TAK1 to TRAF6 in the IL-1 signal transduction pathway. Molecular Cell $\mathbf{5}$ 649-658.

Takaesu G, Ninomiya-Tsuji J, Kishida S, Li X, Stark GR \& Matsumoto K 2001 Interleukin-1 (IL-1) receptor-associated kinase leads to activation of TAK1 by inducing TAB2 translocation in the IL-1 signaling pathway. Molecular and Cellular Biology 21 2475-2484.

Takeuchi O, Hoshino K, Kawai T, Sanjo H, Takada H, Ogawa T, Takeda K \& Akira S 1999 Differential roles of TLR2 and TLR4 in recognition of Gram-negative and Gram-positive bacterial cell wall components. Immunity 11 443-451.

Ulevitch RJ \& Tobias PS 1995 Receptor-dependent mechanisms of cell stimulation by bacterial endotoxin. Annual Review of Immunology 13 437-457.

Wesche H, Korherr C, Kracht M, Falk W, Resch K \& Martin MU $1997 a$ The interleukin-1 receptor accessory protein (IL-1 RAcP) is essential for IL-1-induced activation of interleukin-1 receptorassociated kinase (IRAK) and stress-activated protein kinases (SAP kinases). Journal of Biological Chemistry 272 7727-7731.

Wesche H, Henzel WJ, Shillinglaw W, Li S \& Cao Z 1997b MyD88: an adapter that recruits IRAK to the IL-1 receptor complex. Immunity 7 837-847.

Xia Y, Wu Z, Su B, Murray B \& Karin M 1998 JNKK1 organizes a MAP kinase module through specific and sequential interactions with upstream and downstream components mediated by its amino-terminal extension. Genes and Development 12 3369-3381.

Yamamoto M, Sato S, Mori K, Hoshino K, Takeuchi O, Takeda K \& Akira S 2002 A novel Toll/IL-1 receptor domain-containing adapter that preferentially activates the IFN-beta promoter in the Toll-like receptor signaling. Journal of Immunology 169 6668-6672.

Yamin TT \& Miller DK 1997 The interleukin-1 receptor-associated kinase is degraded by proteasomes following its phosphorylation. Journal of Biological Chemistry 272 21540-21547.

Yin L, Wu L, Wesche H, Arthur CD, White JM, Goeddel DV \& Schreiber RD 2001 Defective lymphotoxin-beta receptor-induced NF-kappaB transcriptional activity in NIK-deficient mice. Science $2912162-2165$.

Received 28 March 2003

Accepted 21 July 2003 